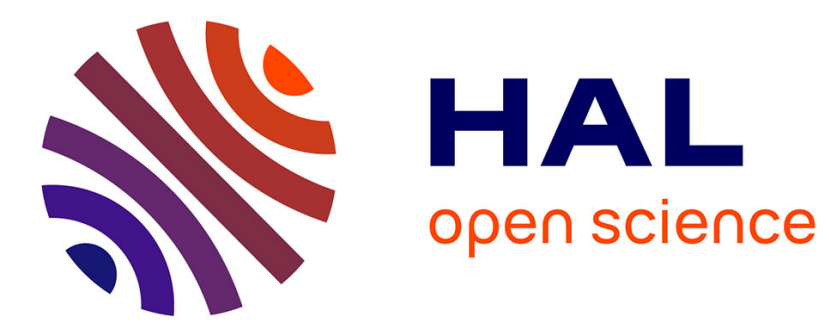

\title{
Radar Propagation Experiment in the North Sea: The Sylt Campaign
}

Andreas Danklmayer, Jörg Förster, Vincent Fabbro, Gregor Biegel, Thorsten Brehm, Paul Colditz, Laurent Castanet, Yvonick Hurtaud

\section{- To cite this version:}

Andreas Danklmayer, Jörg Förster, Vincent Fabbro, Gregor Biegel, Thorsten Brehm, et al.. Radar Propagation Experiment in the North Sea: The Sylt Campaign. IEEE Transactions on Geoscience and Remote Sensing, 2017, 56 (2), pp.835-846. 10.1109/TGRS.2017.2755506 . hal-01710856

\section{HAL Id: hal-01710856 \\ https://hal.science/hal-01710856}

Submitted on 16 Feb 2018

HAL is a multi-disciplinary open access archive for the deposit and dissemination of scientific research documents, whether they are published or not. The documents may come from teaching and research institutions in France or abroad, or from public or private research centers.
L'archive ouverte pluridisciplinaire HAL, est destinée au dépôt et à la diffusion de documents scientifiques de niveau recherche, publiés ou non, émanant des établissements d'enseignement et de recherche français ou étrangers, des laboratoires publics ou privés. 


\section{Radar Propagation Experiment in the North Sea: The Sylt Campaign}

Andreas Danklmayer, Member, IEEE, Jörg Förster, Vincent Fabbro, Gregor Biegel, Thorsten Brehm, Paul Colditz, Laurent Castanet, Yvonick Hurtaud

A. Danklmayer, G. Biegel, T. Brehm, P. Colditz are with the Fraunhofer Institute for High Frequency Physics and Radar Techniques FHR, Wachtberg, Germany (phone: +49-228-9435-350; fax: +49-228-9435-521; e-mail: Andreas.Danklmayer@ fhr.fraunhofer.de).

J. Förster is with the Bundeswehr Technical Center for Ships and Naval Weapons, Naval Technology and Research (WTD 71), Eckernförde, Germany (phone: +49-431-607-4123; fax: +49-431-607-4150; e-mail: JoergFoerster@bundeswehr.org)

V. Fabbro and L. Castanet are with ONERA, The French Aerospace Lab, Electromagnetism and Radar Department (DEMR), F-31055 Toulouse, France (e-mail: Vincent.Fabbro@onera.fr).

Y. Hurtaud is with DGA, Maitrise de l'Information CGN2/SDO, Bruz, France (phone: +33-(0)2-99-42-96-52; fax: +33-(0)2-99-42-90-06; e-mail: yvonick.hurtaud@intradef.gouv.fr).

Abstract - This paper describes an experiment that was carried out in the North Sea off the Sylt island in May 2012 with the aim to study the influence of the maritime boundary layer (MBL) conditions on the propagation of radar signals under low grazing angle geometry and to establish a sea clutter data base at different frequencies with a view to contribute to new sea clutter models. The radar measurements were carried out with the highly versatile radar called MEMPHIS operating in sea configuration at $\mathrm{X}$-, Ka- and W-band simultaneously. As concerns the oceanographic and atmospheric characterization, the collection of measurements was done with a sophisticated suite of sensors partly mounted on the research vessel (RV) Elisabeth Mann Borgese (EMB) and onboard different types of buoys, a catamaran and a tethered balloon. Over a period of 4 days a comprehensive and valuable dataset was successfully collected including clutter measurements under different geometrical configurations and propagation runs with corner reflectors mounted onboard RV EMB. An insight in the overall approach is given together with many measurement examples for a very detailed oceanographic and meteorological characterization and a vast number of multi- 
frequency radar acquisitions, showing the complexity of different parameters that have to be considered for sensor performance assessment and prediction.

Index Terms - millimeter wave propagation, maritime boundary layer, ducting, refractive index, tropospheric propagation effects, radar scattering, sea clutter

\section{INTRODUCTION}

It is well known that radar sensor performance in coastal and maritime environments is particularly affected by meteorological and oceanographic conditions next to the sensor and by the geometry itself. In this context a comprehensive campaign was set up covering several important aspects related to the characterization of the maritime environment in terms of oceanographic and meteorological parameters.

The purpose of the North Sea measurement campaign conducted in May of 2012 was to generate a comprehensive database that allows to investigate propagation effects in the maritime boundary layer as well as to study the behavior of sea clutter under grazing angle and at different geometries. Fraunhofer FHR (previously known as FGAN) has a long tradition in measurement campaigns over the past decades at several locations worldwide Erreur ! Source du renvoi introuvable.-[5]. The reason for campaigns at different geographical locations is that wave propagation may vary considerably depending on the climate and the local tropospheric and oceanographic conditions as well as bathymetry.

The campaign reported in this contribution was carried out on four consecutive days starting from $27^{\text {th }}$ until $30^{\text {th }}$ of May 2012 at the Island of Sylt (Germany), more specifically at the WTD 71 hosted land based test site Bunker Hill and the surrounding area in the North Sea (see Fig. 1). A series of sea clutter measurements together with radar propagation measurements were carried out in collaboration with the WTD 71 (Bundeswehr Technical Center for Ships and Naval Weapons, Naval Technology and Research) being responsible for the oceanographic and meteorological characterization of the environment, i.e. the characterization of the sea surface and the maritime boundary layer by using a set of meteorological and 
oceanographic sensors. This comprises systems mounted onboard RV EMB, moored systems like a multisensor catamaran, a wave rider buoy, a free drifting air-sea interaction buoy and a meteorological buoy as well as other systems (cf. Fig. 7, Fig. 8 ).

All of the radar measurements were carried out by using the multi frequency radar MEMPHIS (Millimeter wave Experimental Multi-frequency Polarimetric High resolution Interferometric System) which is able to measure at three different frequency bands (X-, Ka- and W-band) simultaneously (see Fig. 5).

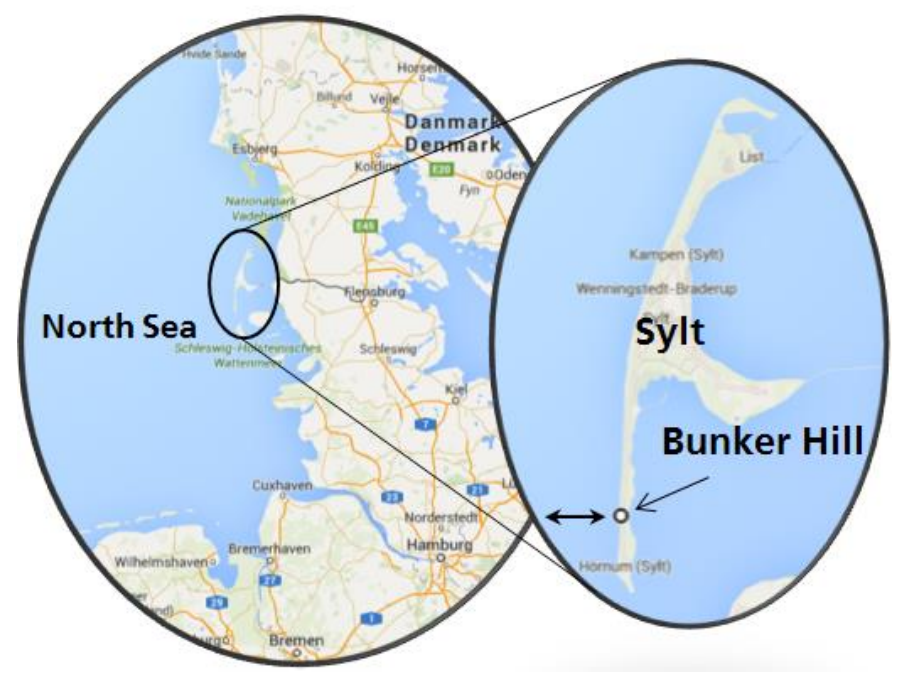

Fig. 1. Location of the test site on the Island of Sylt in the North Sea. The MEMPHIS radar was placed on the so-called "Bunker Hill" indicated as a black circle on the southern part of Sylt. Propagation runs with RV EMB were carried out $270^{\circ}$ (towards west) off Bunker Hill.

This paper which merges and significantly extends two earlier contributions [6] [7] is organized as follows: Subsequent to this introduction the overall approach of the campaign is outlined in Section II. Section III describes the main characteristics of the radar measurement system. In Section IV the meteorological and oceanographic characterization is described together with several examples of acquired data. Section V shows selected examples of radar measurement results, i.e. a subset of the multi-frequency clutter measurements and propagation runs. Finally the conclusions are provided together with an outlook on future work. 
Propagation Conditions above the Sea Surface

The measured radar signature of a target is dependent on several parameters. Not only the RCS (Radar Cross Section) of the target itself and the characteristics of the radar system and the measurement geometry are important but also the environmental conditions of the sea (e.g. sea state and temperature) and the atmosphere, i.e. the propagation media. The maritime boundary layer covers the first tenths of meters above the sea surface and is of significant importance for the sensor performance. Turbulent exchange processes and vertical as well as horizontal temperature and humidity gradients may lead to propagation anomalies like ducting, shift of the horizon, multipath, scintillation, extinction, attenuation and others. As a consequence for the radar signal attenuation, signal fading and probably increase or limitation of detection ranges as well as so-called radar holes, masking targets, may occur. One of the most important quantities to describe the propagation conditions in the maritime boundary layer is the gradient of the so-called modified refractive index $M$ along the height coordinate $\mathrm{z}$. A graph showing a number of different types of $\mathrm{M}$ profiles is provided in Fig. 2. In order to derive this quantity we start with a more fundamental term for the refractivity $N$

$$
N=10^{6} \cdot(n-1)
$$

where $n$ is called the refractive index or also index of refraction, a dimensionless number that describes

how waves propagate in a media with $\mathrm{c}$ the speed of light and $v$ the phase velocity

$$
n=\frac{c}{v}
$$

Then the modified refractive index $\mathrm{M}$ can be written as

$$
M=10^{6} \cdot\left(n-1+\frac{z}{R}\right) \approx N+0,157 z
$$

where $R \approx 6371 \mathrm{~km}$ being the Earth radius.

In order to show the link between the refractive index and the meteorological parameters one can recall the classical Debye formular according to 


$$
N=\frac{77,6}{T} \cdot\left(p+4810 \frac{e}{T}\right)
$$

with temperature $T$ in Kelvin, air pressure $p$ and water vapor pressure in $\mathrm{hPa}$ [8].

Finally we arrive at the exact formulation of the gradient of $\mathrm{M}$ along the $\mathrm{z}$ coordinate

$$
\frac{d M}{d z}=\frac{d N}{d p} \frac{d p}{d z}+\frac{d N}{d T} \frac{d T}{d z}+\frac{d N}{d e} \frac{d e}{d z}+\frac{10^{6}}{R}
$$

where again $\mathrm{p}$ is the air pressure, $T$ corresponds to the air temperature, $e$ represents the water vapor pressure and $R$ is Earth radius. The standard atmosphere corresponds to a set of models that define values for atmospheric temperature, density, pressure and other properties over a wide range of altitudes, where in this case the M-profile is gradually increasing in the lower altitudes, i.e. above the Earth surface (cf. Fig. 2) [9]. Negative gradients lead to refracted rays towards the Earth surface and to ducting where the height of the ducts are determined by the reverse of the negative to the positive sign of the M-gradients $(\mathrm{dM} / \mathrm{dz}=0)$. Frequently observed in the maritime boundary layer are evaporation ducts with maximum duct heights of about $40 \mathrm{~m}$. Non-standard conditions where the gradient of the M-profile is not gradually increasing along the vertical direction are surface based ducts, elevated ducts and complex combinations of different kind of ducts. Ducting may increase the radar horizon and lead to detection range far beyond the geometrical horizon. At the same time anomalous (non-standard) conditions may also increase the clutter return from the sea surface [10]. 


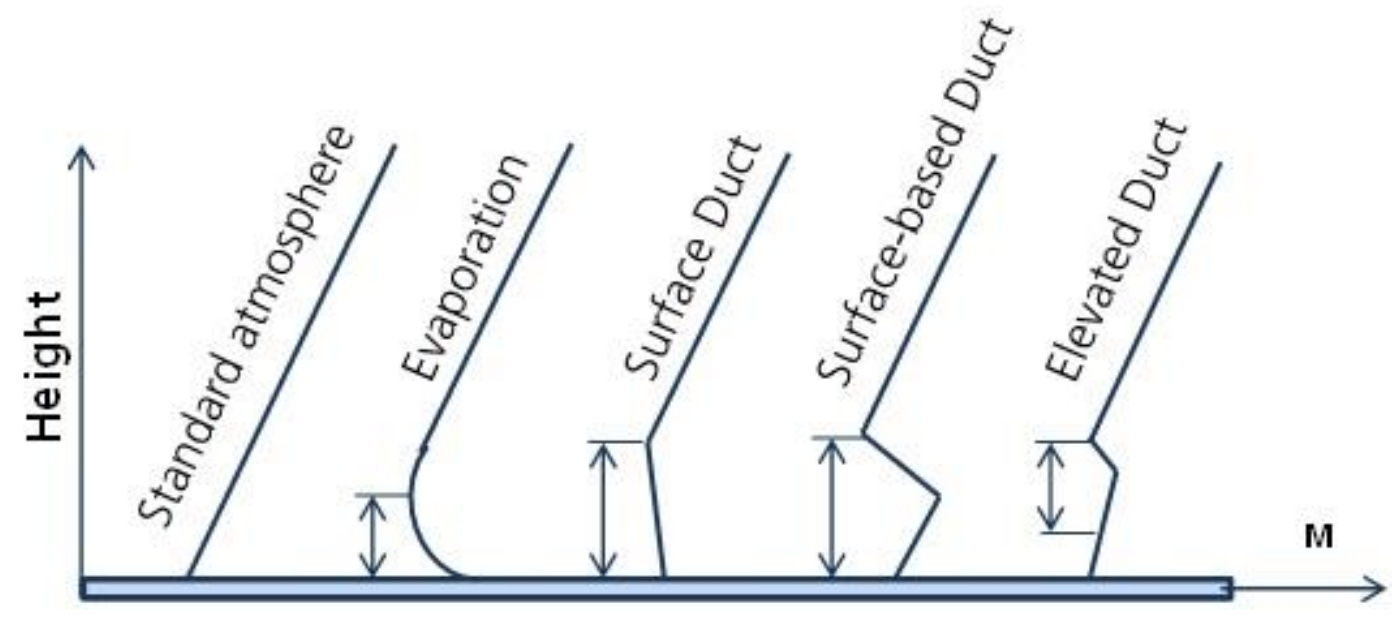

Fig. 2. Depiction of different types of gerneric M-profiles

\section{DESCRIPTION OF THE OVERALL APPROACH}

\section{A. Measurement Setup}

This section describes the overall approach of the experiment. In Fig. 3 the overall set-up of the experiment is shown together with the different sensors and equipment involved. On the left-hand side the MEMPHIS radar located at the so-called Bunker Hill is shown pointing towards the sea for clutter measurements and RV EMB for the propagation runs. Further equipment involved is the catamaran which carries sensors for humidity, air-pressure, air-temperature, wind-speed, sea-temperature and others. Next to the right a waverider buoy is shown which measured the wave height. A multitude of sensors was additionally placed onboard RV EMB which includes four tethersondes carried by a captive balloon which was launched up to 400 meters height using a winch. Several ascents and descents have been performed in order to get a vertical cut of the meteorological parameters like air-temperature, air-humidity, air-pressure and wind speed. Furthermore onboard RV EMB several meteorological sensors at different heights were placed. Next to the right of RV EMB the air-sea interaction buoy can be identified which carries sensors for seatemperature, air-temperature, wind-speed, pressure and others. Another buoy shown most left of Fig. 3 was the meteo-buoy also covering meteorological sensors at different heights. 
All of the sensor data has been carefully processed and displayed to get the best possible overall picture of the actual environmental conditions. It was further possible to collect time series of the sensor data in order to study the temporal variability during daytime and over the entire period of the campaign. Due to the vast amount of measurement data only a subset of measurements is shown in this contribution which should however provide a representative subset of samples of the measurement results that will be shown in more detail in following sections.

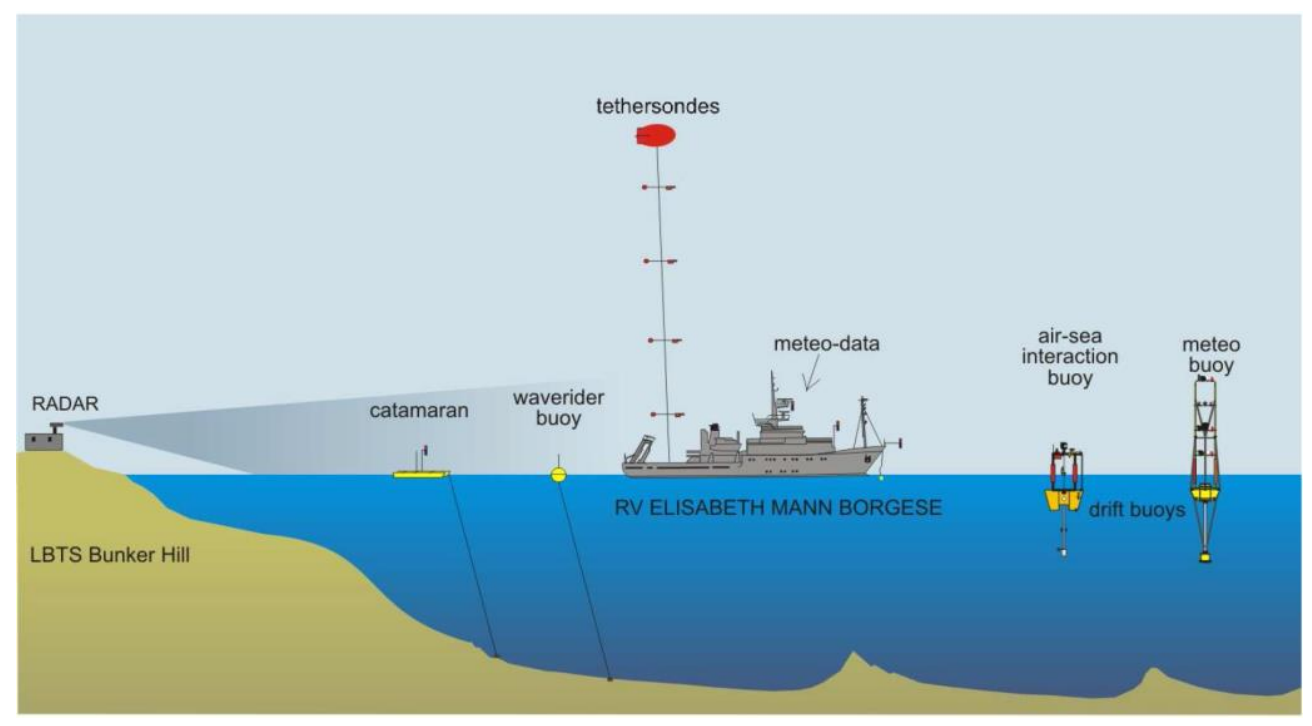

Fig. 3. Sketch of the measurement set-up showing the overall scenario including the radar position at the Island of Sylt termed "Bunker Hill", the RV EMB as well as the air-sea interaction buoy, the meteo buoy, the catamaran and the waverider buoy. Note that the RV EMB was equipped with 4 tethersondes carried by a captive balloon, 4 corner reflectors and several meteorological sensors at different heights.

\section{B. Clutter Measurements}

The clutter measurements under low grazing angles were performed in several configurations. The first mode refers to the case where the measurements were carried out at constant range of the radar footprint but at different azimuth angles. A typical configuration to measure sea clutter at constant range and varying azimuth angle is shown in Fig. 4 a. The beam of the antenna is steered towards the sea surface at a constant distance and will be changed in its azimuth position. This measurement scheme was chosen in order to characterize the response of the sea surface as a function of the azimuth angle. 
For the second measurement mode to measure the backscattering of the sea surface Fig. $4 \mathrm{~b}$ illustrates the corresponding procedure. The idea was to modify the range values but to keep the azimuth angle fixed. If the azimuth angle is steered towards the main direction of the approaching waves, the backscattering from the sea surface becomes a maximum. Since the azimuth direction is kept fix and the values of the range are altered, the clutter of the sea surface can be characterized as a function of the measurement distance and incidence angle. A subset of the huge dataset is provided and discussed in Section V.B.

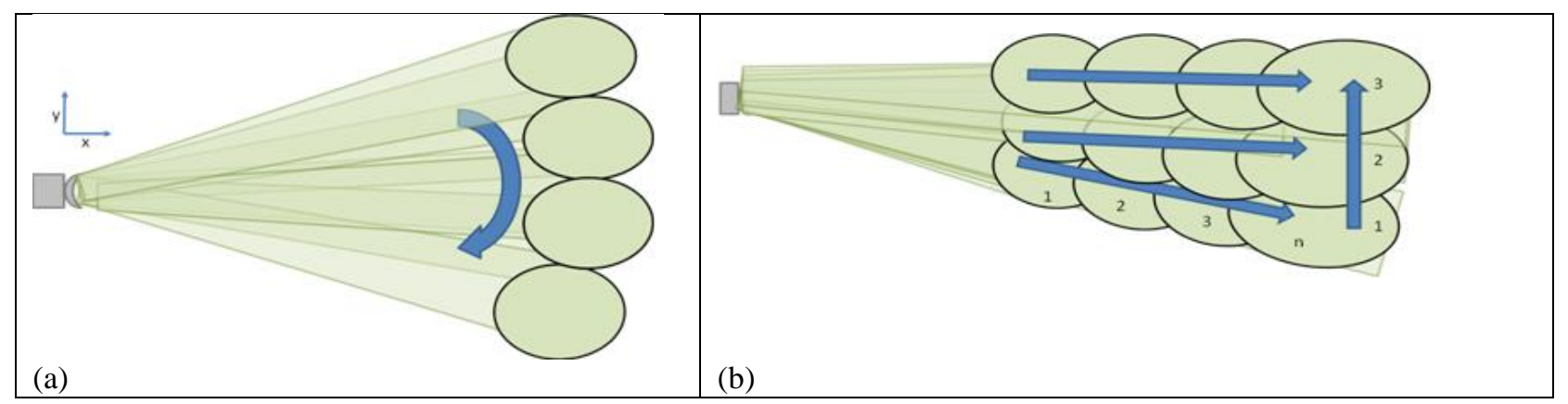

Fig. 4. Depiction of the different clutter acquisition schemes. On the left-hand side (a) the scheme for constant range but different azimuth angles is given, whereas on the right-hand side the acquisition is done for constant azimuth angles but increasing range.

\section{Propagation Runs}

The so called propagation runs were designed to understand and study the influence of the maritime boundary layer on the sensor performance by using corner reflectors mounted on the EMB at two different heights in two directions. Examples of a subset of the measurements are discussed and provided later in Section V.C.

The exact locations onboard RV EMB are shown in Table 1 where the size of the corner reflector was 1.04 m (leg length). An illustration of the corner reflectors mounted onboard RV EMB is shown in Fig. 6 and Fig. 7 .

Table 1. Positions of the corner reflectors at the EMB having a total length of $56.5 \mathrm{~m}$

\begin{tabular}{|l|l|l|l|}
\hline Corner Reflector (CR) & $\begin{array}{l}\text { Height above water } \\
\text { surface [m] }\end{array}$ & $\begin{array}{l}\text { Distance } \\
\text { from bow }\end{array}$ & $\begin{array}{l}\text { Distance } \\
\text { from stern }\end{array}$ \\
\hline CR 1 (towards bow) & $6.09 \mathrm{~m}$ & 0 & $\mathrm{n} / \mathrm{a}$ \\
\hline
\end{tabular}




\begin{tabular}{|l|l|l|l|}
\hline CR 2 (towards bow) & $15.6 \mathrm{~m}$ & $20.93 \mathrm{~m}$ & $\mathrm{n} / \mathrm{a}$ \\
\hline CR 3 (towards stern) & $16.06 \mathrm{~m}$ & $\mathrm{n} / \mathrm{a}$ & $31.81 \mathrm{~m}$ \\
\hline CR 4 (towards stern) & $3.63 \mathrm{~m}$ & $\mathrm{n} / \mathrm{a}$ & 0 \\
\hline
\end{tabular}

\section{MAIN CHARACTERISTICS OF THE MEMPHIS SYSTEM}

The coherent, polarimetric experimental radar MEMPHIS has transmit/receive modules at $10 \mathrm{GHz}$ and in the two mmW-propagation windows $35 \mathrm{GHz}$ and $94 \mathrm{GHz}$. To the best of our knowledge, MEMPHIS is the only system worldwide which is capable to measure radar data simultaneously at the frequency bands mentioned above [11]. The $35 \mathrm{GHz}$ sensor of MEMPHIS can be applied also in full-polarimetric mode, which means that the polarization of transmitted pulses can be switched from puls to puls.

The steerable pedestal was used to adjust the pointing position according to the clutter measurement geometry and for tracking of RV EMB during the so-called in- and outbound runs.

Recorded data comprises files, which contain measurement and calibration parameters as well as the time, distance and the complex amplitude of the co- and cross-polar channels. The front end of the $35 \mathrm{GHz}$ system operates together with an optical video camera allowing comparisons between optical and radar image. Furthermore, the video camera assists in selecting the scenes which are relevant for processing. Further relevant system parameters are given in TABLE 2.

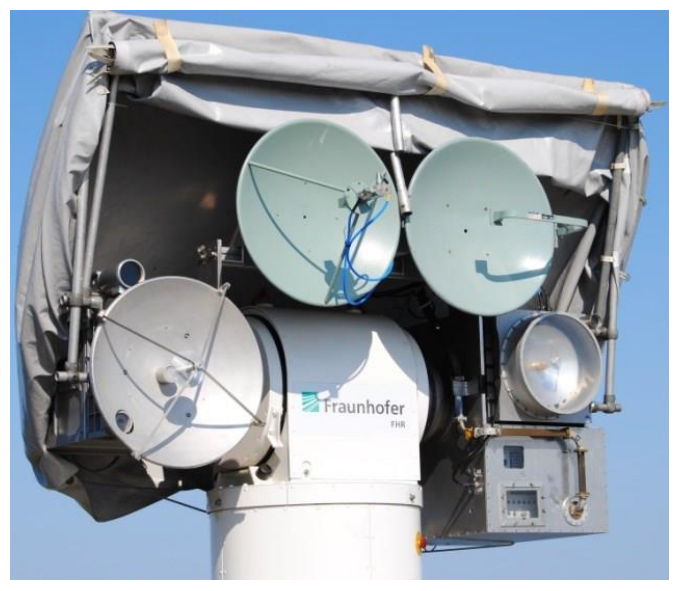


Fig. 5. Depiction of the Memphis front-end mounted on a steerable pedestal. The antenna on the left-hand side belongs to the Kaband system, the smallest antenna on the right hand side to the W-band. The two antennas in between are the quasi-monostatic X-band dishes for transmitting (right) and receiving (left).

TABLE 2 MAIN SYSTEM PARAMETERS OF MEMPHIS

\begin{tabular}{|c|c|c|c|}
\hline & X-Band & Ka-Band & W-Band \\
\hline Transmitter & $9.6 \mathrm{GHz}$ & $35 \mathrm{GHz}$ & $94 \mathrm{GHz}$ \\
\hline Power & $1500 \mathrm{~W}$ & $700 \mathrm{~W}$ & $500 \mathrm{~W}$ \\
\hline PRF & & $2 \mathrm{kHz}$ & \\
\hline Pulse Width & & $400 / 800 \mathrm{~ns}$ & \\
\hline Spectral Purity & & $>70 \mathrm{dBc} / \mathrm{Hz}$ & \\
\hline Phase Stability & & $10^{\circ}$ RMS & \\
\hline \multicolumn{2}{|l|}{ Polarization } & \multicolumn{2}{|c|}{$\begin{array}{l}\text { Linear or circular, } \mathrm{H} / \mathrm{V} \text { or } \mathrm{L} / \mathrm{R} \\
\text { switchable from Pulse to Pulse }\end{array}$} \\
\hline \multicolumn{2}{|l|}{ Waveform } & \multicolumn{2}{|c|}{$\begin{array}{l}\text { Chirp }(100 / 200 \mathrm{~Hz})+\text { stepped } \\
\text { Frequency BW } 800 \mathrm{MHz}\end{array}$} \\
\hline \multicolumn{4}{|l|}{ Receiver } \\
\hline \multicolumn{2}{|l|}{ Dynamic } & \multicolumn{2}{|l|}{$60 \mathrm{~dB}$} \\
\hline Noise Figure & & \multicolumn{2}{|l|}{$15 \mathrm{~dB}$ (SSB) } \\
\hline Polarization & & \multicolumn{2}{|l|}{ Co and cross } \\
\hline Bandwidth & & \multicolumn{2}{|l|}{$100 / 200 \mathrm{MHz}$} \\
\hline Channels & 2 & \multicolumn{2}{|l|}{4} \\
\hline \multicolumn{4}{|l|}{ Antenna } \\
\hline Diameter & $2 \times 60 \mathrm{~cm}$ & $60 \mathrm{~cm}$ & $30 \mathrm{~cm}$ \\
\hline
\end{tabular}

\section{MeteorologicAl And OCEANOGRAPHIC CHARACTERIZATION}

In the marine boundary layer, air-sea interaction processes have an important impact on radar propagation. The range performance near the sea surface depends on meteorological and sea surface conditions whereas strong gradients of humidity and temperature close to the air-water interface are most often the reason for propagation effects such as ducting. For ship borne radars the evaporation duct is the dominant propagation mechanism affecting the maximum detection range. Ducting can also increase sea clutter return within and beyond the geometric horizon [12][10]. Duct characteristics (duct heights, duct structures, duct formation behavior, duct existence, duct vertical and horizontal variability) depend on climatic zones and regional peculiarities. 


\section{A. Sensor Systems for Meteorological and Oceanographic Characterization}

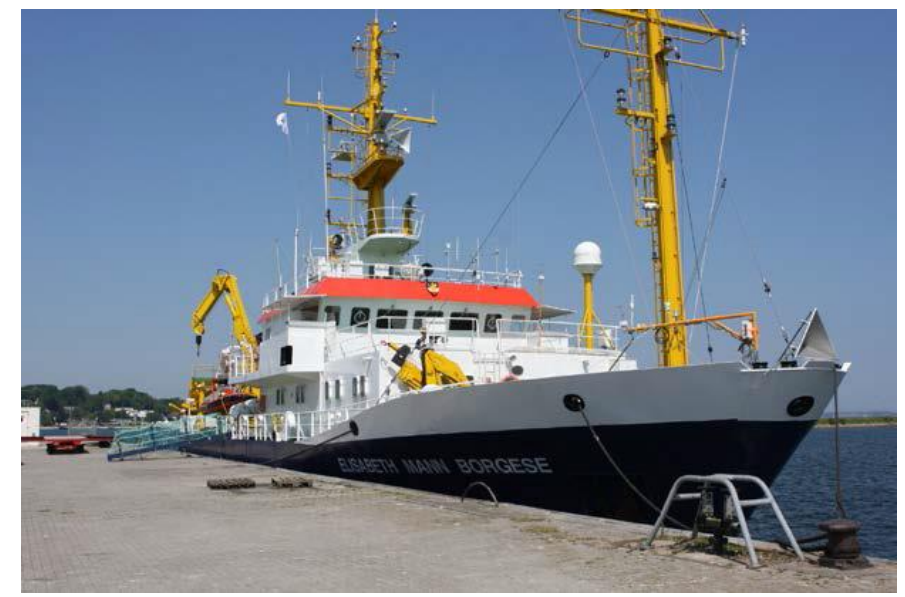

Fig. 6. RV EMB at the pier of the Naval Arsenal in Kiel, Germany. At this location it was equipped with a series of meteorological instruments and 4 corner reflectors mounted at the main mast, the bow and stern of the ship.

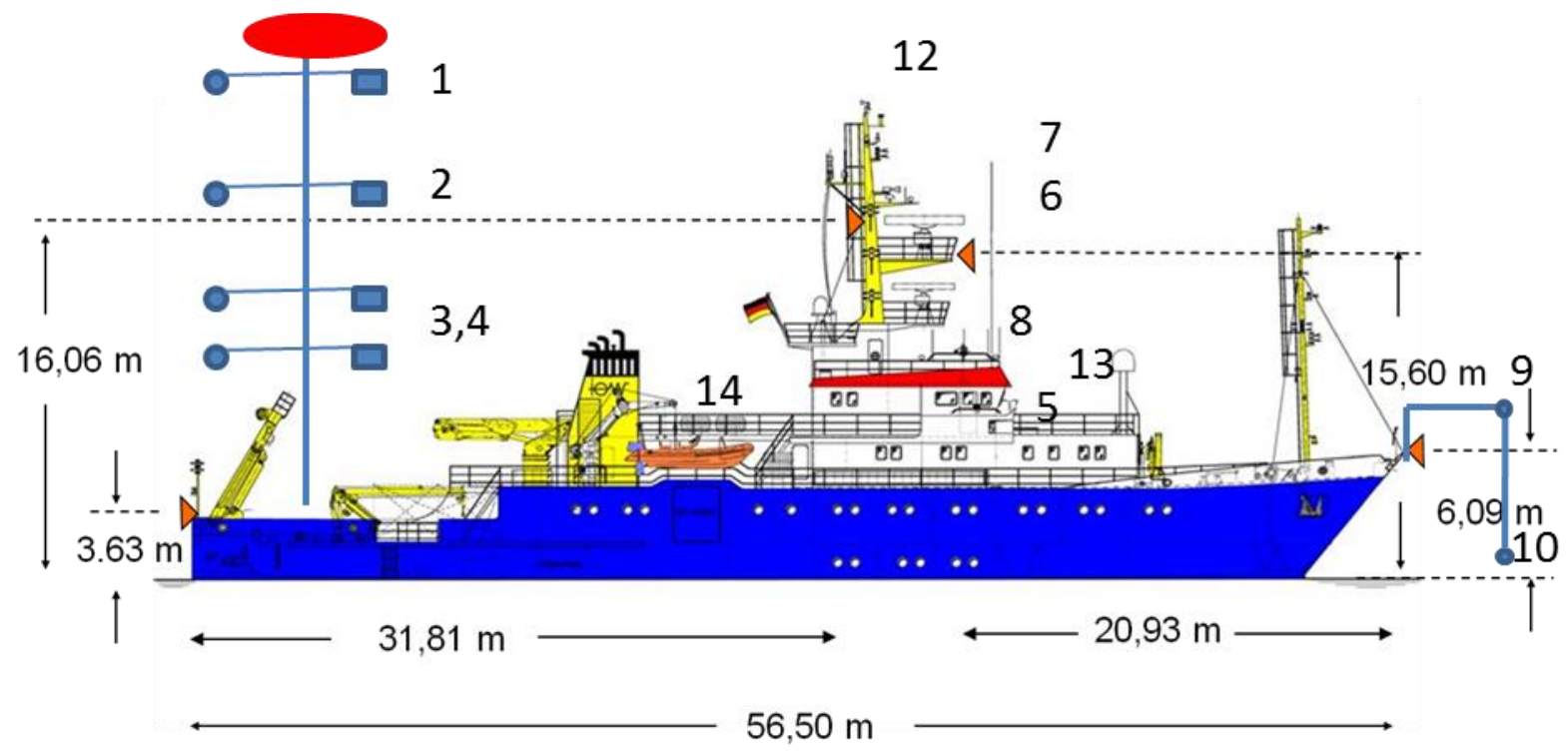

Fig. 7. Depiction of the RV EMB with denoted positions of the different sensors according to Table 1. 
TABLE 3. OVERVIEW OF THE DIFFERENT PARAMETERS THAT WERE CAPTURED WITH CORRESPONDING SENSOR TYPES AND POSITIONS ABOARD THE RV EMB (CF. FIG. 7)

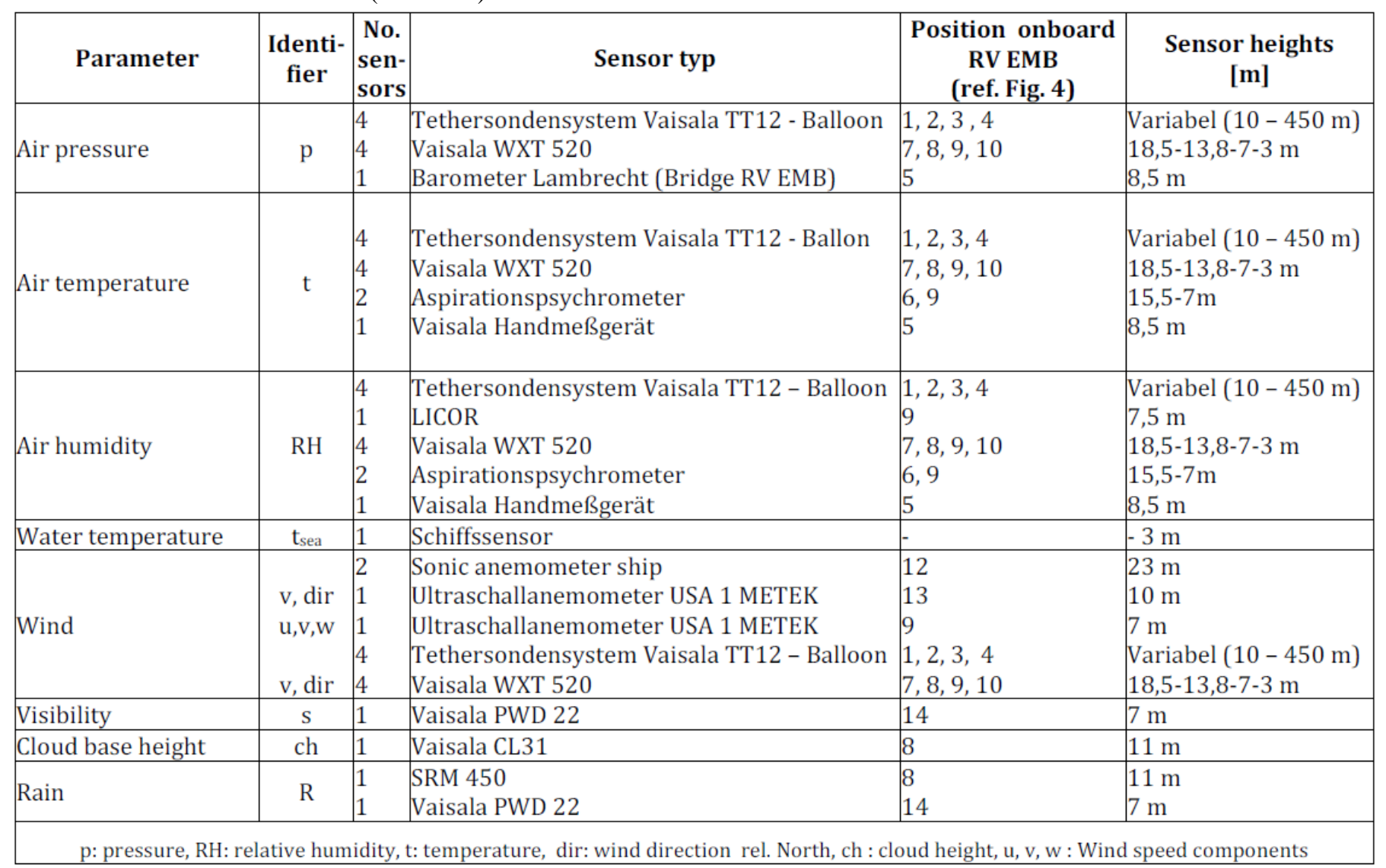




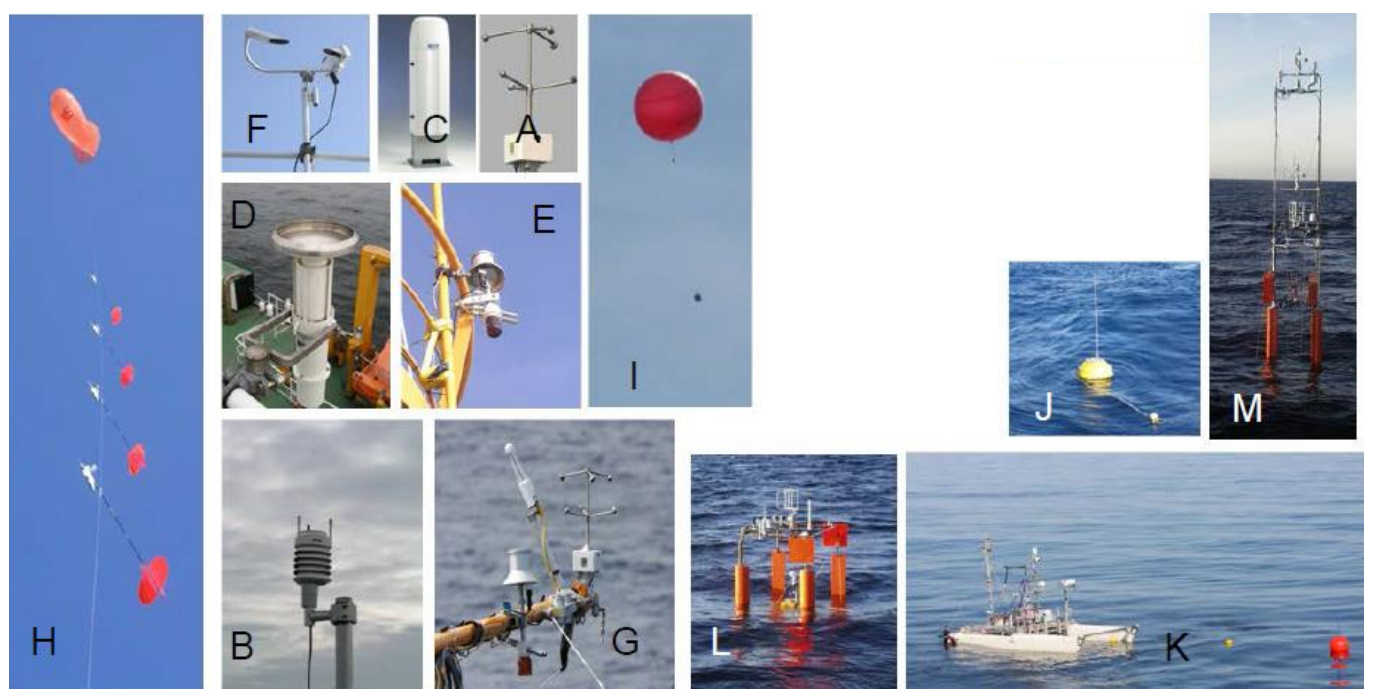

Fig. 8. Sensor systems carried onboard RV EMB and other involved sensors systems to characterize the environmental conditions during the Sylt campaign 2012: A: sonic anemometer (turbulente wind), B: meteorological station (wind speed, wind direction, air temperature, air pressure, air humidity), C: cloud height, D: ship rain gauge, E: psychrometer, F: visibility sensor, G: radiometer, H: tethersonde system, I: radiosonde, J: waverider buoy, K: multisensor catamaran, L: air-sea interaction buoy, M: meteorological buoy

\section{B. Illustrative Examples of Selected Data Set Characterizing the Maritime Environment}

During the first two days of measurements, the weather was set fair and a condition of "glassy sea" was established which not result in strong echoes of the sea surface due to specular reflections of the signals away from the radar. On the other hand, the conditions of ducting were very favorable, allowing to measure signals of the ship-borne corner reflectors up to $31 \mathrm{~km}$ (that is approximately twice as far as the radio horizon in standard conditions).

On the $3^{\text {rd }}$ day the wind speed increased in the morning significantly (up to $20 \mathrm{~m} / \mathrm{s}$ ) resulting in a very rough sea (wave heights from 1.2 to 2 meters observed onboard RV EMB). The measurements of sea clutter under these conditions are interesting and meaningful for further analysis. On the other hand because of the weather conditions, buoys could not be deployed and no releases of radiosondes investigation were made. 
The change of the wind conditions in the middle of the campaign allowed obtaining interesting conditions. At the beginning of the week ducting conditions prevailed and for the following days the measurements of sea clutter was possible. On the third day, the characterization of the maritime boundary layer was only possible by using ship sensors. Sea surface conditions were measured with the waverider buoy.

This section shows and discusses only a small subset of data that have been acquired with the comprehensive suite of sensors that were deployed during the campaign. In the top panel of Fig. 9 the wave height during the period of four consecutive days of measurements with the waverider buoy is shown. In order to recall the parameters provided in the legend of Fig. 9 the significant wave height $\mathrm{H}_{1 / 3}$ is defined as the average height of the highest one-third waves in a wave spectrum, wheras $H_{1 / 10}$ is the height of the highest $10 \%$ of the waves. $\mathrm{H}_{\max }$ is the highest wave (approximately 2 times the significant wave height) and the average wave height is defined as the height of the wave with $50 \%$ of probability of occurrence. The plot confirms that during the first half of the measurement campaign rather smooth sea conditions were prevailing, while in the second half stronger wind conditions existed that led to a significant increase of the wave height, thus covering a variation of different wave heights. The bottom panel shows the respective optical images acquired daily. 

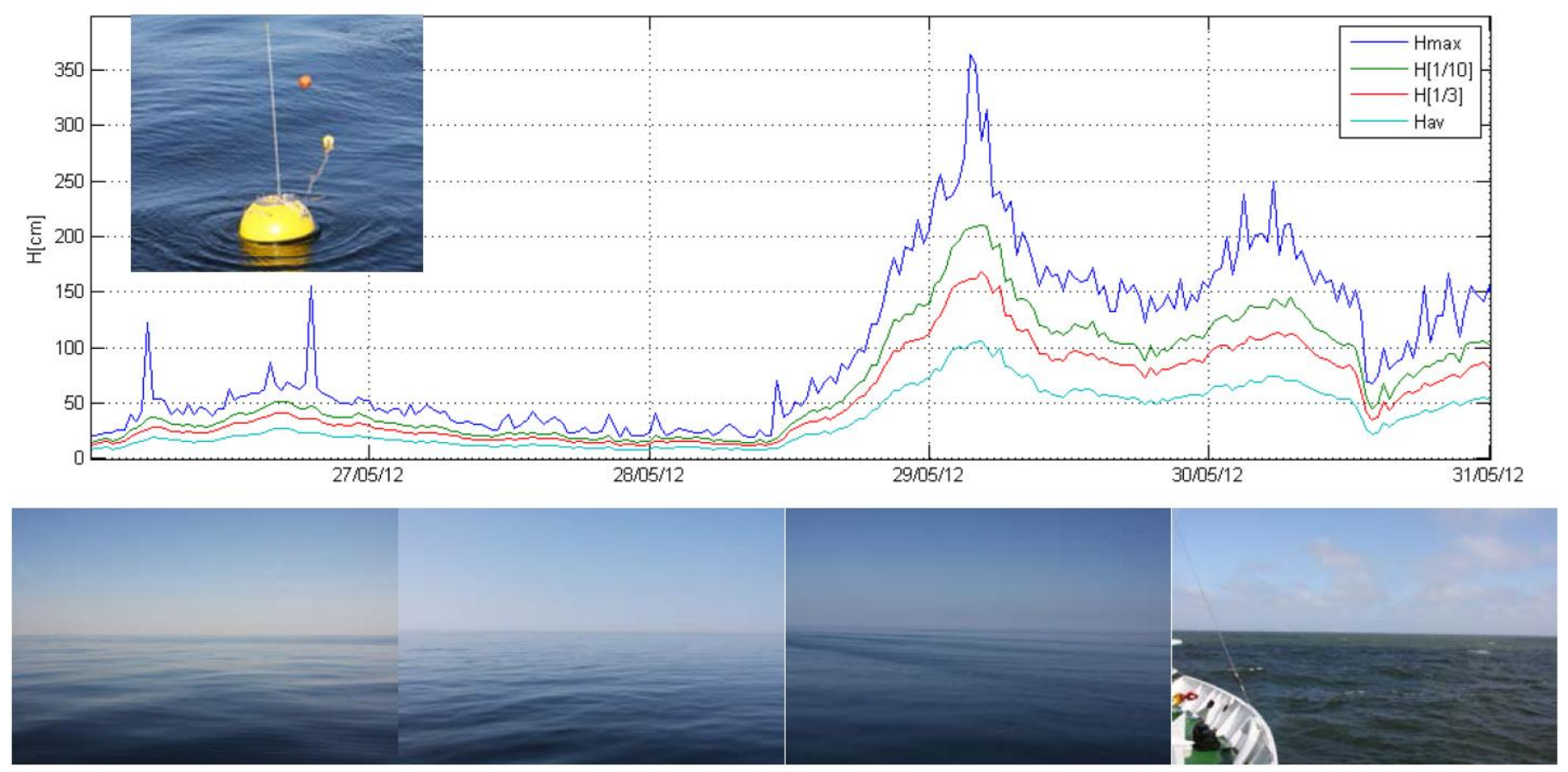

26.05.2012-08:00 UTC 27.05. $2012-16: 30$ UTC $\quad 28.05 .2012-09: 15$ UTC $\quad 29.05 .2012-09: 00$ UTC

Fig. 9. Top panel: depiction of the measurements by the waverider buoy during the campaign period starting from $26^{\text {th }}$ of May until $31^{\text {st }}$ of May. The plot confirms that during the first part of the campaign smooth conditions were prevailing whereas in the second part the wave heights increased. Such variety is particularly very interesting in order to study the effects due to the changes within the maritime environment. The lower panel shows corresponding photos of the sea surface for the different days for visual impression.

An interesting type of plot is given in Fig. 10 which displays the air to sea temperature difference (ASTD) in Kelvin at the horizontal axes versus the air sea vapor pressure difference (ASVPD) in [hPa] on the vertical [13].

This graphical illustration is used to characterize the overall propagation conditions in terms of Radar and EO (Electrooptical) sub-/superrefraction conditions. The term subrefraction refers to the case where the detection of Radar/EO systems is less than standard. However if superrefraction conditions prevail the radar or EO system may exceed the detection ranges compared to standard conditions. For the radar case the detection of objects far beyond the optical horizon might become feasible which was confirmed during earlier campaigns. 
The reason why also the EO case is included in this analysis is the fact that in previous campaigns the synergy between EO and radar was investigated several times thus this could serve as a reference for some readers. At this point we would like to stress the fact that the humidity is much less important for the EO case compared to radar. The two sectors below the red line indicate the radar superrefractive conditions whereas the sectors above indicate radar subrefractive conditions. For the EO domain the separation is such that the right handside indicate EO superrefractive conditions and the left-hand side subrefractive conditions. The color coding of the curves refer to the different days. During the entire period of the campaign, the radar propagation conditions where almost always superrefractive except for some time periods on $27^{\text {th }}$ of May.

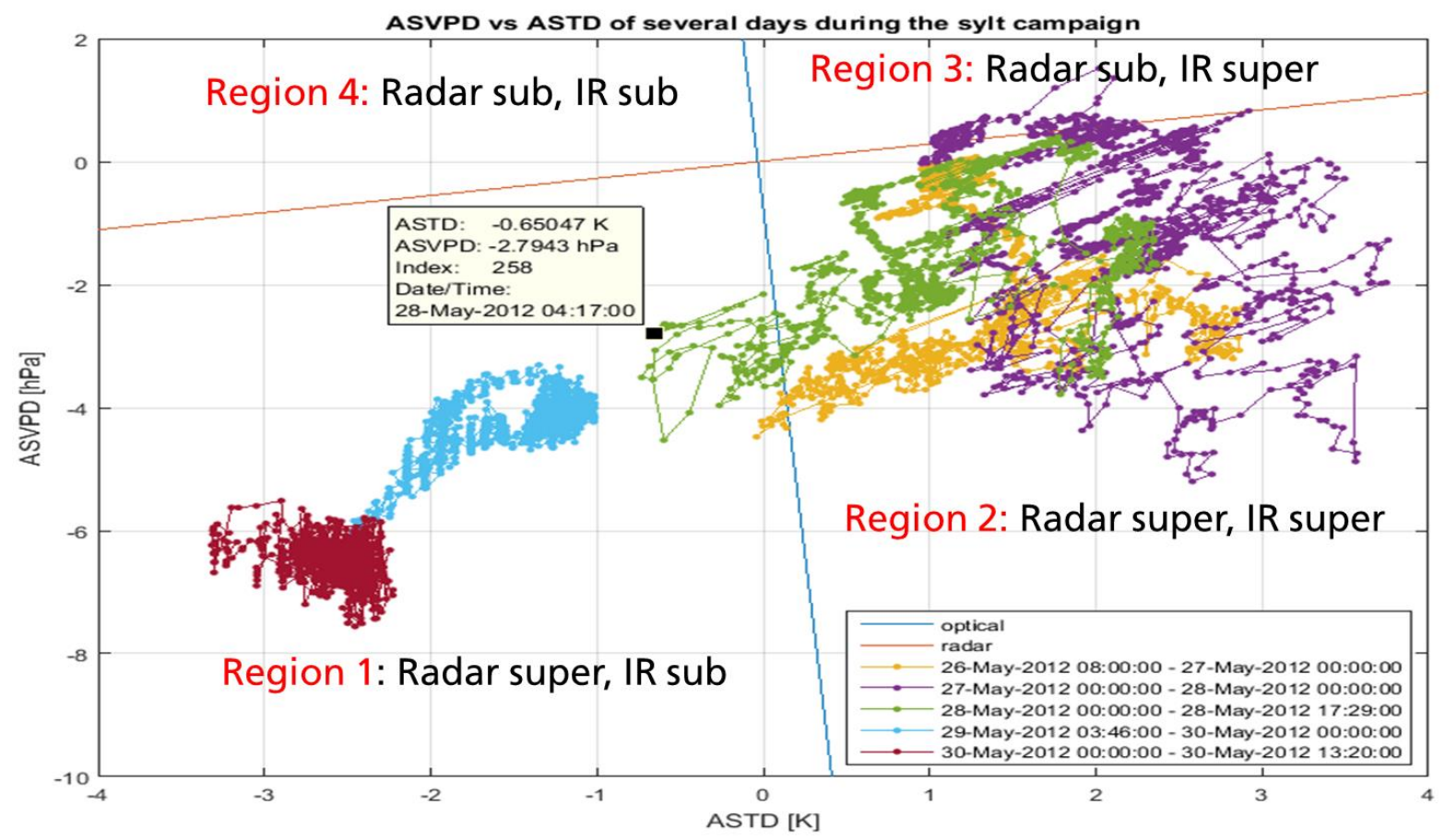

Fig. 10. Depiction of the ASVPD (Air Sea Vapour Pressure Difference $[\mathrm{hPa}]$ on the vertical dimension vs. the ASTD (Air Sea Temperature Difference) in $[\mathrm{K}]$ on the horizontal dimension for different days starting from $26^{\text {th }}$ until $30^{\text {th }}$ of May 2012 where the color coding refers to the different days according to the legend.

In Fig. 11 the altitude versus time profiles of the tethersondes are shown in detail. The maximum height that was reached was $450 \mathrm{~m}$ for the highest sonde where the separation in height between the sondes was 
$50 \mathrm{~m}, 30 \mathrm{~m}$, and $5 \mathrm{~m}$ (from top). The duration for launching and lowering of the sondes was approximately $10 \mathrm{~min}$. The respective color coding is provided in the legend.

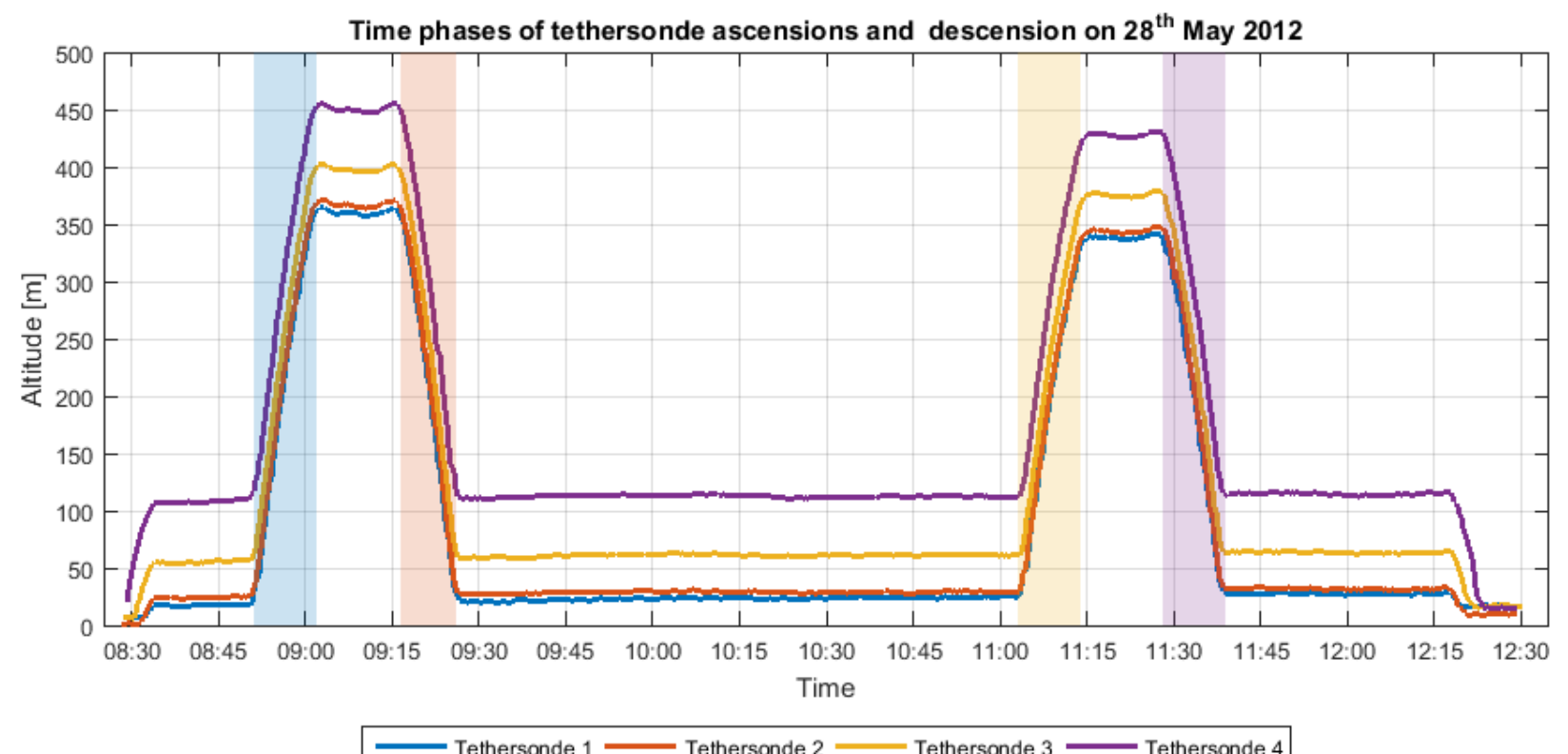

Fig. 11. Depiction of the tethersondes ascends and descends which were launched by a captive balloon on the $28^{\text {th }}$ of May. The maximum height reached by the highest sonde was $450 \mathrm{~m}$. Note that the color-coding of the curves corresponds to the different thethersondes. The colors of the highlighted sectors are used later in Fig. 12 to identify the curves of the different parameters with respect to the time phase.

In Fig. 12 a subset of data with respect to the maritime boundary layer is shown. The plots that represent the parameters of air temperature, air pressure, relative humidity and wind speed versus height are derived from the measurements of the tethersondes. The orange curve resulted from the first descent with a comparable duration. The yellow and the purple curves represent also the ascent and descent of the tethersondes but at a later instance of time (after approximately 30 minutes). The temperature profiles are indicating a strong temperature inversion with a maximum height of about $170 \mathrm{~m}$. 

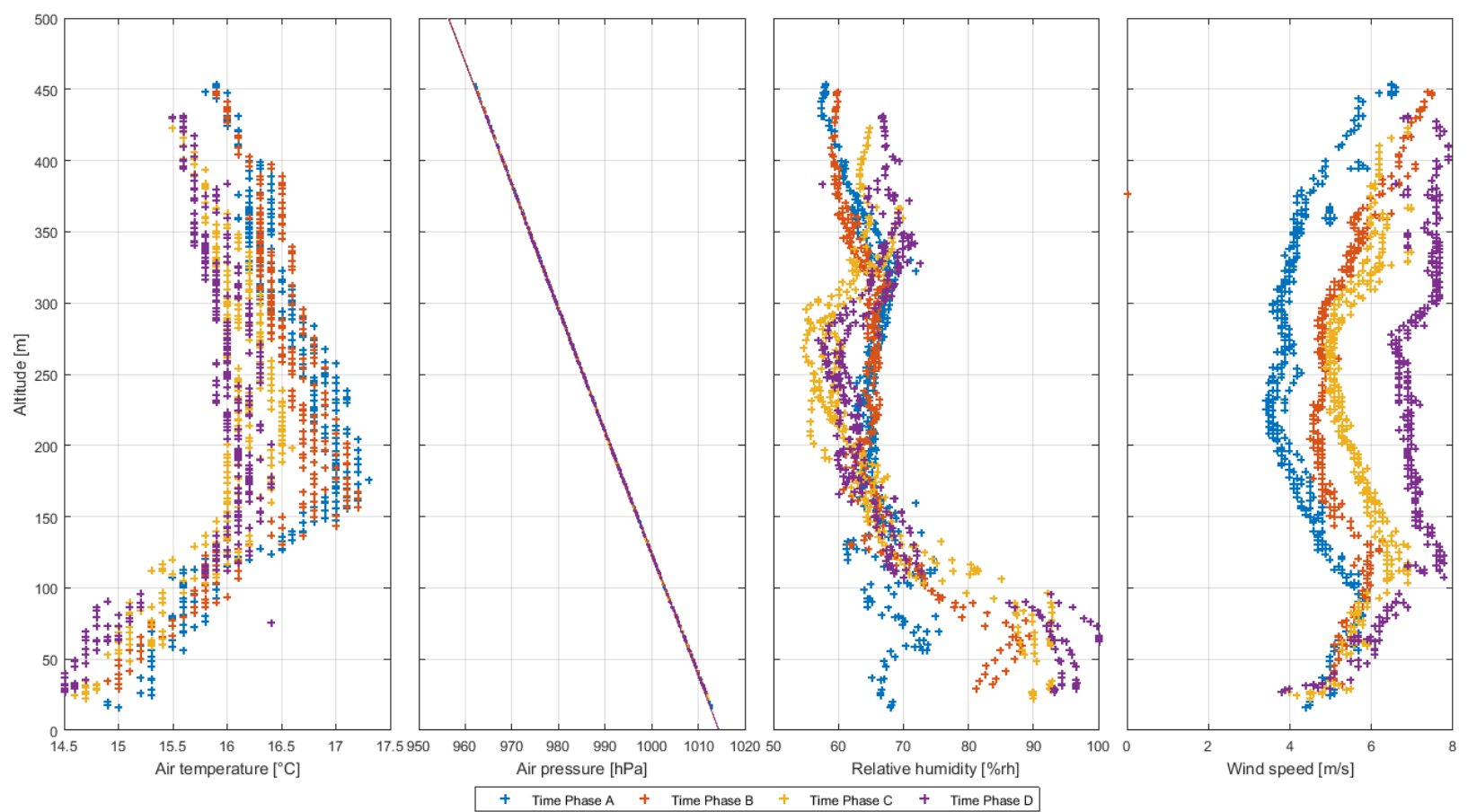

Fig. 12. Depiction of the air temperature $\left[{ }^{\circ} \mathrm{C}\right]$, air-pressure $[\mathrm{hPa}]$, relative humidity $[\% \mathrm{rh}]$ and wind speed $[\mathrm{m} / \mathrm{s}]$ versus height, where the color coding corresponds to the different time phases based on tethersonde measurements carried out on May $28^{\text {th }}$ (ref. Fig.10) . It can be clearly observed that the pressure remains stable over the time period whereas the air temperature, relative humidity, and the wind speed changes more rapidly over time.

In Fig. 13 the modified refractivity versus height is plotted which is derived from the combination of different sensors measurements according to their respective elevation, namely the tethersondes, the shipborne sensors, the catamaran sensors and the buoys. The different colors of the curves correspond to different incidences of time on 27th (left) and 28th (right) of May 2012. The upper part (> $20 \mathrm{~m}$ ) of the blue curve stems from the first ascent of the sondes where the raise time was approximately $10 \mathrm{~min}$ as can be seen from Fig. 11.

Beside the pronounced evaporation duct also an elevated duct could be captured. The lower elevations of the plot were derived from the shipborne sensors (4 WXT 520 sensors at different heights) and the catamaran. 

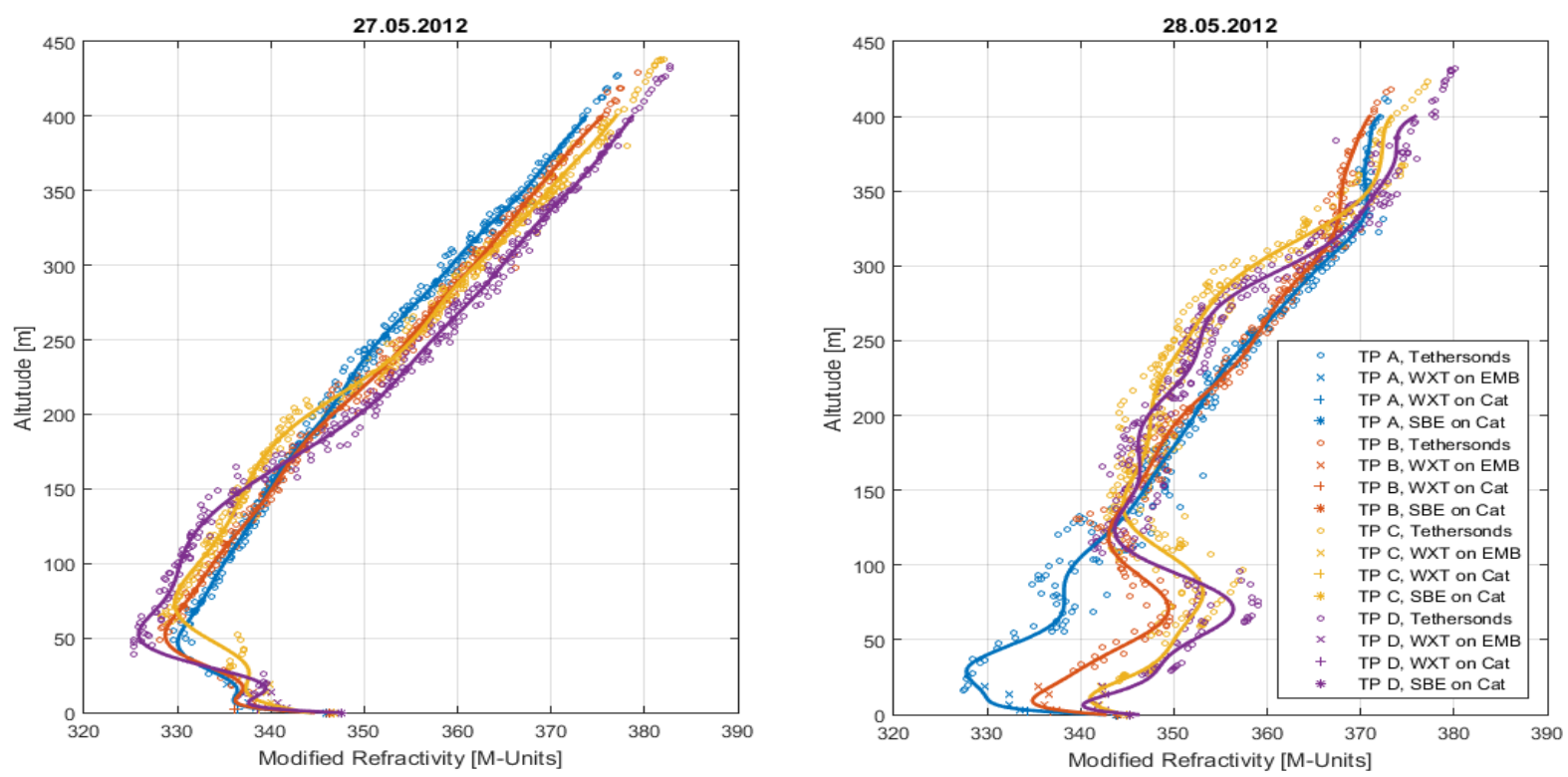

Fig. 13. Depiction of the modified refractivity versus height based on a multitude of oceanographic and meteorological sensors for the $27^{\text {th }}$ and $28^{\text {th }}$ of May. In order to cover the heights below the thethersondes on the captive balloons the WXT sensors on the RV EMB were used at $3 \mathrm{~m}, 7 \mathrm{~m}, 13.8 \mathrm{~m}$ and $18.5 \mathrm{~m}$ together with the sensors onboard the catamaran (cf. the legend at the right hand side for more details). It can be clearly observed that the variability during the ascents and descents was larger on the $28^{\text {th }}$ of May. For the left plot the curves show a simultaneous existence of an evaporation duct and a surface base duct, whereas on the right hand side the evaporation duct is superimposed by an elevated duct.

\section{RADAR MEASUREMENT RESULTS}

\section{A. Overview of the acquired Radar Data Base}

Table 4 gives an overview of the acquired radar database. The comprehensive data base was collected in a period of 4 consecutive measurement days $\left(27^{\text {th }}-30^{\text {th }}\right.$ of May 2012). The measurements can be subdivided in terms of type, i.e. propagation measurements, measurements towards the pole, calibration measurements, and clutter measurements, respectively. For the clutter measurements different configurations were chosen. First, as mentioned above, at a constant range and with changes of the azimuth angles by an angle interval of $15^{\circ}$, or by doing a continuous scan over the entire azimuth sector. Second the azimuth angle was kept at a fixed value and the range distance was modified in steps of $500 \mathrm{~m}$ or the antenna beam was steered continuously from near to far range. Fully polarimetric radars measure the complete scattering matrix and offer - compared to single polarimetric systems - a higher information content, which can be exploited especially for the case of the Ka-band data. 
TABLE 4 OVERVIEW OF THE ACQUIRED RADAR DATA SET DURING FOUR CONSECUTIVE DAYS INCLUDING CLUTTER-, CALIBRATION-, POLE- AND PROPAGATION MEASUREMENTS.

\begin{tabular}{|c|c|c|c|c|}
\hline Day & $\begin{array}{l}\text { Number of } \\
\text { propagation } \\
\text { measurements }\end{array}$ & Number of clutter measurements & Pole & Calibration \\
\hline 27.05 . & $\begin{array}{l}2 \text { Inbound, } \\
2 \text { Outbound }\end{array}$ & $\begin{array}{l}\mathbf{2 8} \text { files in total; } \\
4 \text { constant range/ modified Azimuth meas- } \\
\text { urements; } 225-315^{\circ} \text { in steps of } 15^{\circ} \text { at } 4 \text { dif- } \\
\text { ferent ranges }\end{array}$ & 6 & 6 \\
\hline 28.05 & $\begin{array}{l}2 \text { Inbound, } \\
2 \text { Outbound }\end{array}$ & $\begin{array}{c}68 \text { files in total; } \\
4 \text { variable azimuth measurements starting } \\
\text { from } 225-315^{\circ} \text { in steps of } 15^{\circ} ; \\
3 \text { continuous scans, } \\
4 \text { data sets at constant azimuth variation of } \\
\text { the range in } 13 \text { steps }\end{array}$ & 14 & 8 \\
\hline 29.05 & $\begin{array}{l}2 \text { Inbound, } \\
2 \text { Outbound }\end{array}$ & $\begin{array}{l}117 \text { files in total; } \\
6 \text { variable azimuth measurements from 225- } \\
315^{\circ} \text { in steps of } 15^{\circ} \text { at } 6 \text { different ranges, } \\
5 \text { continuous scans }\end{array}$ & 18 & 5 \\
\hline 30.05 & $\begin{array}{l}1 \text { Inbound, } \\
1 \text { Outbound }\end{array}$ & $\begin{array}{c}73 \text { files in total; } \\
5 \text { Azimuth measurements } \\
5 \text { continuous scans } \\
3 \text { Datensets at constant azimuth and stepwise } \\
\text { modification in the range direction }\end{array}$ & 12 & 5 \\
\hline
\end{tabular}

\section{B. Selected Examples of Clutter Data}

In Fig. 14 a subset of the comprehensive data set acquired during the Sylt campaign is provided. The four data set show the response of the sea under grazing angle geometry at distance between $2779 \mathrm{~m}$ near range and $3221 \mathrm{~m}$ far range which corresponds to a footprint of roughly $450 \mathrm{~m}$. The images in the left column show the data acquired under the azimuth angle geometry of $225^{\circ}$ which corresponds to the direction orthogonal to the wave moving direction onshore. The images provided in the right column correspond to the pointing direction of the radar towards $315^{\circ}$ azimuth angle against the wave moving direction. In the top row the results from the $\mathrm{X}$-band measurements are given, whereas the lower row corresponds to the Kaband measurements. The measurement time for both acquisitions was $30 \mathrm{~s}$ starting on $29^{\text {th }}$ of May 2012 at 8:02:45 (UTC) for $225^{\circ}$ and 8:10:55 for $315^{\circ}$ respectively. This campaign has permitted to acquire sea clutter measurements to study sea NRCS (Normalized Radar Cross Section) and Doppler spectrum variations with grazing and azimuth angle, frequency, polarization, sea state and wind variations. 

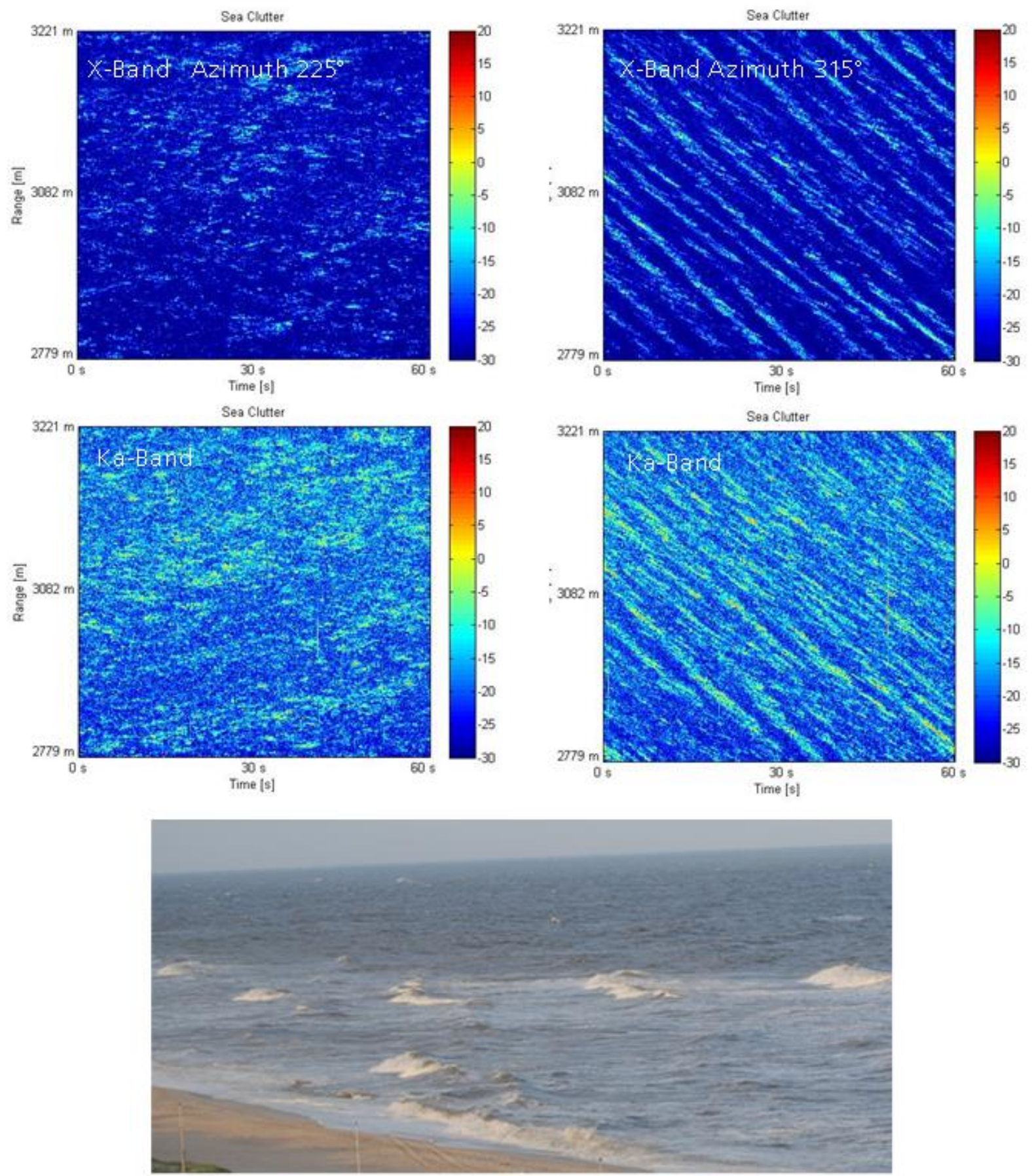

Fig. 14. Example of a clutter data set acquired at two different frequencies, the X-band vs. the Ka-band at $225^{\circ}$ (left column) and $315^{\circ}$ azimuth angle (right column). With increasing azimuth angle starting at $225^{\circ}$ the response of the sea surface increased with the maximum response from $315^{\circ}$ where the waves were moving towards the radar beam direction. The plots show the measurements over a time period of $30 \mathrm{~s}$. In the lower panel the optical image is given for visual comparison at an acquisition angle of about $225^{\circ}$ azimuth direction during the acquisition as seen from the radar position. 


\section{Selected Data of the Propagation Runs}

In this section a selected sub-set of data is shown. Two examples of measurements are provided from the X-band and Ka-band. In Fig. 15 we show the extracted signatures of two corner reflectors (CR) measured at X-band at two different heights. The main difference in the measurement geometry of the two panels is the height of the corner-reflectors which results in a different periodicity and differences in the amplitude of the interference pattern. The CR with the lower position (top panel) exhibits less frequent changes of the minima and maxima but the multipath fading is higher compared to the $\mathrm{CR}$ at the higher position (lower panel).
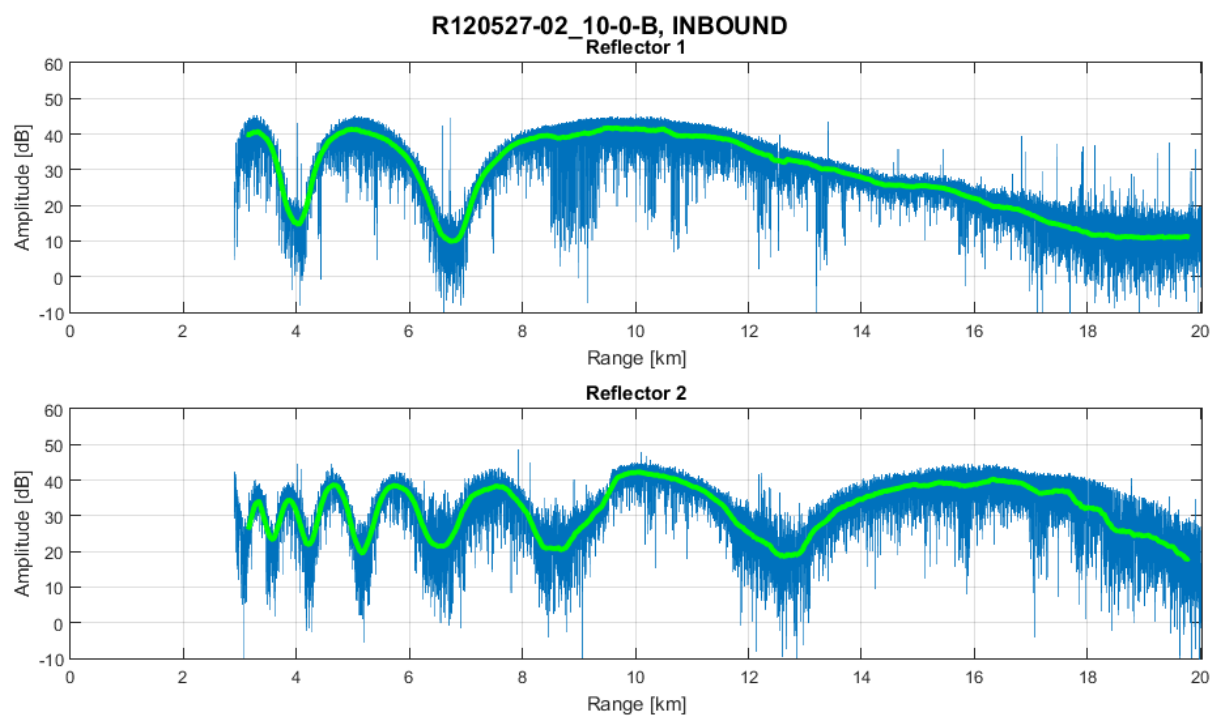

Fig. 15. Depiction of the extracted signatures of two corner reflectors in $\mathrm{X}$ band $(10 \mathrm{GHz})$ at the two distinct heights of $6.09 \mathrm{~m}$ for reflector 1 (top panel) and reflector 2 at $15.6 \mathrm{~m}$ height (lower panel). The greenline is a smoothed and filtered version of the original version in blue.

In Fig. 16 the measurements of the same run are provided but at Ka-band. Basically a quite similar behavior can be observed if compared to X-band. However the periodicity of the interference pattern is higher compared to the X-band acquisitions because of the shorter wavelength. As expected the lower corner reflector exhibits a reduced periodicity compared to the higher one. The difference between the heights is $9.5 \mathrm{~m}$. 
During the data assessment a newly developed tool called ASR (Aligner, Shifer, Ranger) was used for the first time. A MATLAB $®$ code was implemented by Fraunhofer FHR which allows the processing of MEMPHIS data such that range profiles and signatures of moving ships can be extracted more conveniently. The tool is based on existing software developed by Fraunhofer FHR but considerably adds value.

Previously used ideas of finding the maxima in each range line were profoundly improved to a more dynamic and robust implementation by using a correlation function to unambiguously track a moving ship signature. A graphical user interface (GUI) was realized to display and monitor the results and diverse functions were implemented to export the generated data in different data types for post processing.

The implemented tool provides a valuable aid to analyze MEMPHIS radar data. The extracted signatures serve as an important input for the comparison with the modelling based on the parabolic wave equation (PWE) as well as related RFCR (Refractivity from corner reflector) inversions [14][15]. Considering the direct problem, PWE models should be improved in particular to better model reflection and diffraction on the sea surface [16][17]. Considering inverse problem, RFCR allows testing the RFC inversion parametrization and algorithms Erreur ! Source du renvoi introuvable.[18].
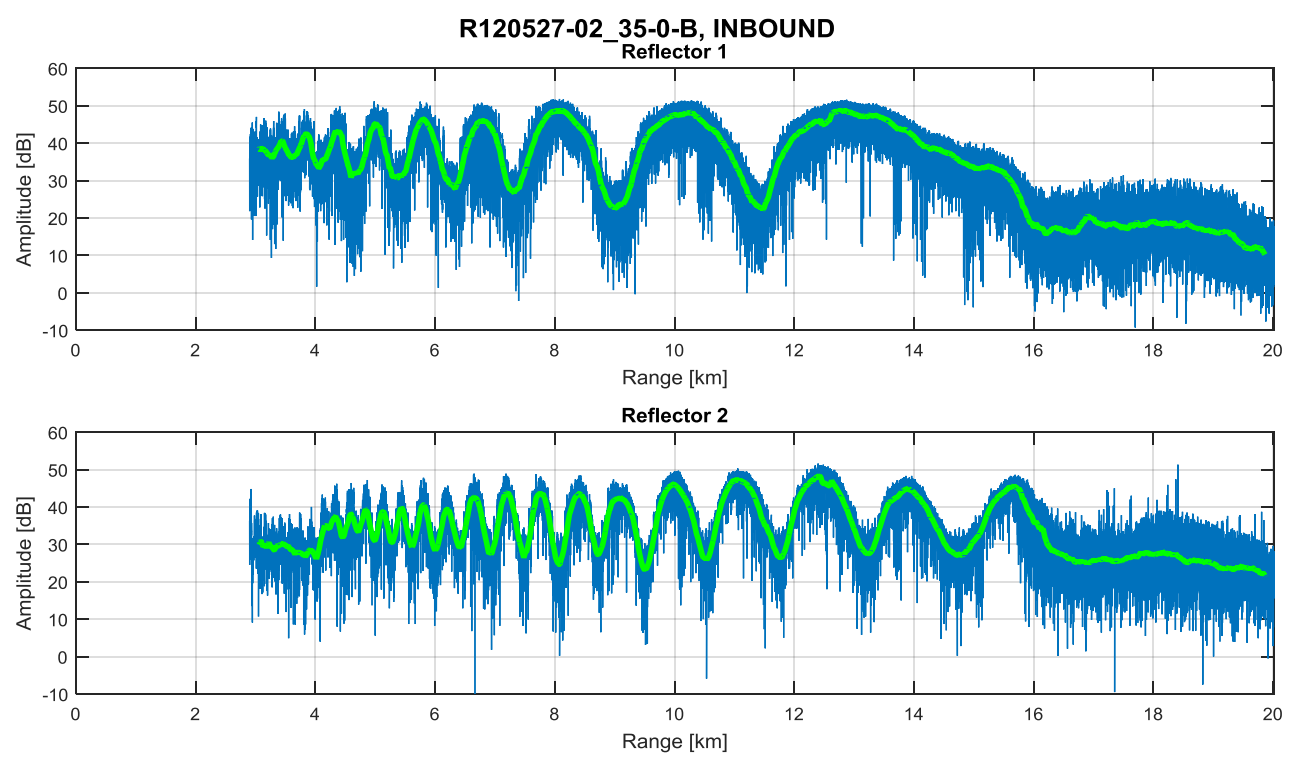

Fig. 16. Depiction of the extracted signatures of two corner reflectors in Ka band (35 GHz) at the two distinct heights of $6.09 \mathrm{~m}$ for reflector 1 (top panel) and reflector 2 at $15.6 \mathrm{~m}$ height (lower panel) 


\section{CONCLuSiONS}

A valuable and complete dataset was successfully acquired during the campaign performed in the North Sea region at the island of Sylt. Not only a variety of radar measurements were carried out including clutter measurements and propagation measurements but also the sophisticated characterization of the tropospheric parameters in the maritime layer was performed including the complex oceanographic characterization. Next to the overall description of the campaign many illustrative examples of measurements have been provided. This includes examples for the characterization of the atmosphere and the oceanographic conditions. Furthermore examples of sea clutter data were provided at different frequencies and incidence angles. For the study of propagation effects some examples of measurements at inbound and outbound runs were shown in comparison for two different corner-reflector heights and at two different frequency bands: X-band and Ka-band. The expected behavior of multipath due to constructive and destructive interference was confirmed, thanks to an improved strategy and implementation of the extraction of signatures of single corner reflectors installed at different heights and in different directions onboard RV EMB. The current results already provide plentiful evidence of the suitability of the chosen experimental approach. In a future contribution it is planned to focus on the in-depth scientific analysis of the sea clutter and to address further the modelling aspect by using a model based on the parabolic wave equation [20][21] with the respective concurrent meteorological input parameters. Possible topics of in-depth analysis could be to compare the outputs of different evaporation duct models with the measured profiles as well as to compare refractivity profiles computed by a Numerical Weather Prediction (NWP) model. Furthermore the RFC technique could be possibly applied to the in- and outbound runs and compared with the meteorological measurements. Finally the clutter data could be used to validate clutter models such as the GIT model. All of the ideas above are possible candidates for further research but additional time and efforts respectively funding is needed to make progress towards this endeavor. 


\section{ACKNOWLEDGEMENT}

The measurement campaign was carried out as a part of and within the frame of a German French Technical Agreement TA-119 "Modelling and measurements of sea clutter at centimeter and millimeter bands; application to atmospheric refractivity assessment", involving Fraunhofer FHR, WTD 71, DGA-MI, and ONERA.

\section{REFERENCES}

[1] A. Danklmayer, G. Biegel, T. Brehm, S. Sieger and J. Förster, "Millimeter wave propagation above the sea surface during the Squirrel campaign," 2015 16th International Radar Symposium (IRS), Dresden, 2015, pp. 300-304. doi: 10.1109/IRS.2015.7226386

[2] H. Essen, H. H. Fuchs, "Two-way propagation within the marine boundary layer at X-, Ka- and Wband," in Proc. of European Conference on Propagation and Systems ECPS, 2005, vol. 15, 15 -18 March 2005, Brest, France

[3] A. Danklmayer, S. Sieger, "Propagation Experiment in the littoral at $94 \mathrm{GHz}$, Proceedings of the IEEE International Symposium on Antennas and Propagation and North American Radio Science Meeting, Vancouver, BC, Canada, 2015

[4] H. Essen, H.-H. Fuchs, "Microwave and Millimeterwave propagation within Marine Boundary Layers”, Proceedings of German Microwave Conference (GeMIC) 2006, Germany

[5] A. Danklmayer, T. Brehm, G. Biegel, J. Förster, "Multi-frequency propagation measurements over a horizontal path above the sea surface in the Baltic Sea”, Proceedings of EUCAP 2013, Gothenberg, Sweden

[6] A. Danklmayer, J. Förster, P. Colditz, G. Biegel, T. Brehm, "North Sea Millimeterwave Propagation Experiment: The Sylt campaign”, Proceedings of the International Radar Conference (IRS) 2016, Krakow, Poland 
[7] A. Danklmayer, J. Förster, P. Colditz, G. Biegel, and Brehm, T., "Multi-frequency RF-Measurements and Characterization of Propagation Conditions in the Maritime Boundary Layer", Proceedings of the AP-S/URSI International Symposion, San Juan, PR 2016

[8] B. B. Bean, and E. J. Dutton, 1968: Radio Meteorology. Dover Publications, 435 pp.

[9] Y. Hurtaud, \& J. Claverie, (2015, June), "Geophysical Information Inputs for Computing the Performance of EM Systems in Littoral Environments", The Radio Science Bulletin No 353, pp. 10 16.

[10] I. M. Brooks, A. K. Goroch, and D. P. Rogers, 1999: “Observations of Strong Surface Radar Ducts over the Persian Gulf', J. Appl. Meteor. 38, 1293-1310, doi: 10.1175/15200450(1999)038<1293:OOSSRD>2.0.CO;2.

[11] H. Schimpf, H. Essen, S. Böhmsdorff, and T. Brehm, "MEMPHIS - A Fully Polarimetric Experimental Radar", Proceedings of the IEEE International Geoscience and Remote Sensing Symposium IGARSS, vol. 3, pp. 1714-1716, June 2002

[12] S. C. Lee, D. E. Maurer, \& K. L. Musser (1988), "Predicting clutter during anomalous propagation conditions”, Johns Hopkins APL Technical Digest, Volume 9, Number 2, pp. 101-109.

[13] J. L. Forand, A study into infrared search and track, Technical Report 2003-044, Defense R\&D Canada - Valcatier, DRDC, June 2002, Obtained via internet last visit on 2nd of August 2017 , http://cradpdf.drdc-rddc.gc.ca/PDFS/unc21/p519660.pdf

[14] H. Essen, A. Danklmayer, J. Förster, M. Behn, Y. Hurtaud, V. Fabbro, L. Castanet, "Joint French German Radar Measurements for the Determination of the Refractive Index in the Maritime Boundary Layer”, Proc. SPIE 8535, Optics in Atmospheric Propagation and Adaptive Systems XV, 853505 (1 November 2012); doi: 10.1117/12.924793, 9 pages

[15] A. Danklmayer, H. Essen, G. Biegel, J. Förster, M. Behn, Y. Hurtaud, V. Fabbro, L. Castanet, "Retrieval of the atmospheric propagation conditions over the sea surface based on sea clutter 
measurements", Proceedings of the International Geoscience and Remote Sensing Symposium (IGARSS), Munich, Germany 2012

[16] R. Douvenot , V. Fabbro, P. Gerstoft, C. Bourlier, J. Saillard, "Real Time Refractivity from Clutter Using a Best Fit Approach Improved with Physical Information,” RADIO SCIENCE, VOL. 45, RS1007, doi:10.1029/2009RS004137, 2010

[17] R. Douvenot, V. Fabbro, and K. Elis, "Parameter-Based Rules for the Definition of Detectable Ducts for an RFC System", IEEE Transactions on Antennas and Propagation, Vol. 62, No. 11, pp. 5696 5705, November 2014, doi: 10.1109/TAP.2014.2354680.

[18] V.Fabbro, M. Noblet, R. Lahaye, P. Nicolas, C. Bourlier,, "Propagation modeling using the Split Step Fourier method: Ground boundary conditions analysis and acceleration by GPU," 2014 International Radar Conference, Lille, 2014, pp. 1-6.

[19] V. Fabbro, C. Bourlier, P.F. Combes P, "Forward propagation modelling above rough surfaces by the parabolic wave equation. Introduction of the shadowing effect," Journal of Electromagnetic Waves and Applications, Progress in Electromagnetic Research, Series Book vol. 58, pp 243-269, 2006.

[20] M. Levy, Parabolic Equation Methods for Electromagnetic Wave Propagation, IET 2000

[21] P. Zhang, L. Bai, Z. Wu, and L. Guo, "Applying the Parabolic Equation to Tropospheric Groundwave Propagation, A review of recent achievements and significant milestones", IEEE Antennas \& Propagation Magazine, June 2016, p. 31-44 